\title{
Rethinking the changing structures of rural local government - state power, rural politics and local political strategies?
}

Abstract: There is a notable absence in contemporary rural studies - of both a theoretical and empirical nature - concerning the changing nature of rural local government. Despite the scale and significance of successive rounds of local government reorganisation in the UK, very little has been written on this topic from a rural perspective. Instead research on local political change has tended to concentrate on local governance and local partnerships - on the extra-governmental aspects of the governance system - rather than on local government itself. In contrast, this paper draws upon strategic relational state theory to explore the changing structures and institutions of rural local government, and analyse how these can be related to the changing state strategies of those groups which are politically powerful in rural areas. In this respect, the paper draws on current and previous rounds of local government reorganisation to illustrate how new objects of governance, new state strategies and new hegemonic projects are emerging as a consequence of such restructuring processes.

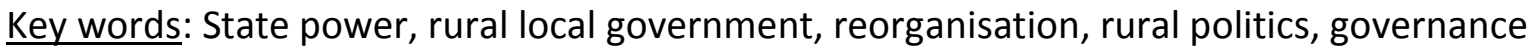

\section{Introduction}

Rural areas have recently been subject to widespread demographic, social and economic change (Woods, 2005; Woods and Goodwin, 2003). They are increasingly linked into wider spheres of production and consumption, and the traditional divisions between urban and rural or town and country have become difficult to draw (Pahl, 2008). Instead research now emphasises the connections between city and countryside, and points to continuums - social, spatial and experiential - rather than divisions (ibid.). Analyses of rural change have also increasingly drawn on wider sets of economic, social and cultural literatures ('the cultural turn' - see Horton, 2008; Holloway and Kneafsey, 2004; Cloke, 1997) and the 'rural' itself is now investigated as a social construct (Rye, 2006; Phillips et al, 2001; Phillips, 1998), along with researchers analysing the countryside as a space of commodification, consumption and deregulated production (Marsden, 2004). Analysts are also drawing on post-structural discourses of representation to discuss rural 'others' (Cloke, 2006; Hubbard, 2005; Little, 2002) and are using political-economy literatures to investigate issues such as poverty, deprivation and homelessness (Milbourne, 2006; Cloke, Milbourne and Widdowfield, 2002; Mackinnon, 2001). In terms of rural political change, studies have recently been published which draw on actor-network theory (Murdoch 1998, 2001) and associative concepts of power and citizenship (Woods, 2008).

As part and parcel of this incorporation of wider social theory into rural research, the last decade has also seen a significant volume of work on rural governance, stimulated by a theme issue of this journal in 1998 (Marsden and Murdoch, 1998). Work in this area has variously looked at the conceptual and theoretical underpinnings of rural governance (Goodwin, 1998; Woods and Goodwin, 2003); at the formation and operation of rural partnerships (Edwards et al, 2001; Jones and Little, 2000); and at community engagement and participation (Day, 1998; Edwards, 1998; Herbert-Cheshire, 2000). It has produced a range of empirical material on rural governance drawn from Europe (Moseley 2003), the 
USA (Radin et al, 2003), Australia (Cheshire, 2006) and New Zealand (Welch, 2002). This work has, however, tended to focus on what might be termed the 'extra-governmental' aspects of rural governance, such as partnerships, rather than looking at the traditional structures of local government itself.

Alongside this empirical work on rural governance, we have also seen major developments in the conceptual and theoretical frameworks of urban and regional government, producing work, for instance, on regime theory, regulation theory, growth machines and coalitions, institutional thickness, and learning regions (for discussions on one or more of these approaches see Healey, 2006; Goodwin et al, 2006; Jones et al, 2005; Brenner et al, 2003; Mossberger and Stoker, 2001; Amin, 1999; MacLeod and Goodwin, 1999a,b; Jones, 1998; Judge et al, 1995; Peck and Tickell, 1992, 1995). Yet very little of this material has been used by those interested in rural change. Indeed, despite the acceptance that the division between 'rural' and 'urban' is outmoded, and that changes in both spaces are driven by similar sets of social and economic structures operating at a wider level, the separation between the two continues to hold in analyses of political and institutional change. The advances made in our understanding of urban government have not been adopted to the same extent in the rural literature.

This arguably leaves a critical area of rural change under-examined and undertheorised. In this context, Hoggart and Panagiua (2001) have argued that the use of a regulationist approach within rural studies - which focuses on "the overall analysis of (capital) accumulation as a socially embedded, socially regulated process" (Jessop 1997a: 526) - can shed light on continued state restructuring. However, Goodwin (2006) has cautioned that regulationist ideas will need to be linked to other concepts in order to fully inform research on government, governance and state institutions. Although he suggests that there is "tremendous scope" for undertaking this task, he also points to the dangers of eclecticism and of attempting to combine fundamentally incompatible theoretical frameworks (Goodwin, 2006: 313).

In order to avoid these dangers, this paper draws on strategic-relational state theory (Jessop, 2008; 1997b,c) to analyse the restructuring of rural local government. The strategic-relational approach (SRA) is grounded in an inclusive or integral understanding of the economy and state respectively. It draws our attention to the relationship between processes of capital accumulation and specific hegemonic political or state projects, with an emphasis on how political, intellectual and moral leadership is "mediated through a complex ensemble of institutions, organizations and forces operating within, orientated toward or located at a distance from the juridico-political state apparatus" (Jessop, 1997c: 52).

Section 2 situates the rest of the paper by looking at the process of local government reorganisation in the UK since 1974, and highlights some issues that are now arising in rural areas as a result of the latest 'set piece' reform by the state. Section 3 considers in more detail how the SRA can help us understand the complex mechanisms and processes resulting from the restructuring of rural local government. In particular, it explores how the SRA allows us to analyse and understand the shifting sites, scales and spaces of state activity that are produced by local government reorganisation. Section 4 uses empirical research from a previous round of local government restructuring to highlight how the changing institutions of the state can both inform - and indeed are themselves informed by (changing) local political strategies (and intellectual and moral leadership) in the course of policy development. This example also highlights how the SRA can help to provide a suitable 
framework within which to analyse the consequences of the current reorganisation of English local government, as well as the restructuring of rural local government that has recently taken place elsewhere, such as that in the USA, Canada and New Zealand. Section 5 concludes the paper by presenting the broader methodological and conceptual implications of the study, and considering the extent to which the research helps us understand the changing shape and nature of rural local government and the rural local state.

\section{State restructuring in rural areas and local government reorganisation in the UK- 'set piece' reform?}

The structures of local government in rural England are currently undergoing a major reorganisation, designed to introduce 'unitary' authorities which are responsible for the delivery of all key services within a local government area. This is the latest in a series of reforms which have seen the UK's system of local government change greatly since its inception late in the nineteenth century. There have been several attempts to reorganise and revise its distinctive characteristics, with successive reorganisations differing in their intended effects (Keith-Lucas and Richards, 1978). Political, administrative and managerial rationales have all been put forward to justify changes to the local government system, with different reorganisations leading to various changes in the structure, function, finance and internal management of that system.

Historically, the structure of local government in the UK has consisted of county (rural) / county boroughs (urban), district and parish councils. In 1974 a major round of structural reform led to the creation of 47 county councils; 6 metropolitan county councils in the largest conurbations outside London (both of which were responsible for 'strategic' services such as Planning, Education and Transport), and 333 lower-tier districts / boroughs (with responsibility for 'lower-level' services such as Housing, Recreation and Environmental Health). Additionally, parish councils in England and community councils in Wales provided a third tier of local government which could address specific local issues such as footpaths and lighting (Dearlove, 1979).

The reforms of the 1970s were criticised as making neither geographic nor economic sense (Elcock, 1994) and the contemporary reform of local government in England can be traced back to the end of the 1980s and a desire to improve the accountability of the twotier structure introduced in 1974. This structure had failed to inspire local political loyalties, and its suggested reform provided the Conservative Government with the opportunity to introduce a new council tax to replace the unpopular 'poll tax' (Byrne, 1994). Consequently, in 1991 Government consultation papers proposed changes to the structure of local government in Wales, Scotland and England (Welsh Office, 1991; Scottish Office, 1992; Department of Environment - DoE, 1991). In Wales this led to the direct imposition of twenty-two unitary single-tier authorities (replacing 8 counties and 37 district councils), whilst in Scotland twenty-five single-tier mainland councils were created (plus the maintenance of the existing three island councils) from 1 April 1996 (Leach, 1995).

In contrast, a degree of consultation did take place in England through the creation of a Local Government Commission (LGC) under the chairmanship of Sir John Banham. But the outcomes of the consultation were to an extent circumscribed by the Government who stated that in any new system the "two-tier structure (is) to be the exception rather than 
the norm" (Press Release, DoE, 1993: 30). In January 1995 the Commission published its final recommendations for England's future local government which included a two-tier structure for most of rural England, but, unsurprisingly, these were not accepted by the Government which favoured a single-tier solution. This led to the whole Commission resigning and the Government issued new guidelines which again pressed for a unitary solution (McHardy and Simmons, 1995). The final outcome of the 1990s reorganisation led to the creation of 46 largely urban unitary authorities alongside a largely rural two-tier structure with 34 'shire' counties split into 239 local districts.

Further proposals for rural unitary authorities in northern England emerged as part of the regional devolution agenda promoted by the New Labour Government from 1997 onwards, although the rejection of regional assemblies following a referendum in 2004 delayed progress (Gore and Fothergill, 2007). Notwithstanding this, the 2006 local government White Paper - Strong and Prosperous Communities (Department of Communities and Local Government - DCLG, 2006) - revived the interest in creating further unitary arrangements and requested applications for reform by local authorities, again according to set criteria. Twenty six proposals were subsequently received from counties and districts seeking unitary status (DCLG, 2007). In March 2007 the Government announced that 16 of these had been shortlisted to go forward for public consultation, following which nine new Unitary Councils were created (the former counties of Cornwall, Durham, Northumberland, Shropshire and Wiltshire, and four new authorities emerging from an amalgamation of existing districts in Bedfordshire and Cheshire) In addition, reviews are currently taking place for Norfolk, Suffolk and Devon, which may result in further unitary councils being created in these areas (The Electoral Commission, 2009).

The nine new authorities became operational on 1 April 2009 (see Figure 1). Whilst it is too early to consider the full impact of structural and political change what appears to be emerging in predominantly rural areas such as Cornwall, and Shropshire are concerns with improving both the efficiency and accountability of service provision. For example, the new authority in Shropshire has developed a series of 'area headquarters' and 17 'customer service points' throughout the county in order to provide internet access to council services and a 'telly talk' link to facilitate a face-to-face discussion with advisers from the local authority and other organisations (Shropshire Council, 2009). In addition, it is proposed to create 27 Local Joint Committees across Shropshire with the power to make decisions about the local delivery of a range of services and hold senior officers and elected members to account. They will also have a delegated budget to spend on local priorities. Strategically, these local committees will feed into three new 'strategic' sub-county partnerships that will cover north, central and south Shropshire in order to try and secure efficiencies in strategic policy making that supports locally-sensitive service delivery (ibid.).

\section{INSERT FIGURE 1 HERE}

In Cornwall, similar moves are afoot and the authority is currently creating new governance structures to deliver policy at a range of scales. 19 Community Networks based on the main towns and their neighbouring parishes have been set up in order to try and devolve decision-making to a local level. It is also intended that they will have some devolved budgets to spend on local projects (One Cornwall, 2009). These networks will 'fit' within three service delivery areas for all services - East, Central and West Cornwall, with the intention that this will "help to fulfil [a] commitment to localism" whilst simultaneously 
provide financial viability and efficiency gains through internal and external partnership working (ibid.). In many ways then, the decision to reorganise the local government structure in these rural areas has already set off a chain of structural and policy changes. Our next section will consider some conceptual work which we feel can be used to analyse the consequences and implications of these changes in local government. Although we draw on the UK for our empirical material, there is no reason why this conceptual approach should not be used to analyse and inform studies of local government change more broadly.

\section{State structures and state strategies: the strategic-relational approach to state theory}

We should not, of course, be surprised at this territorial restructuring. Neil Brenner has recently drawn our attention to the ways in which "historically specific configurations of state space are produced and incessantly reworked" (Brenner, 2004: 76). In other words, new geographies of the state, or 'new state spaces' in his words, are constantly being produced as part and parcel of the shifting nature of state institutions and political strategies (ibid.). Brenner's own empirical work concentrates on how cities and city regions represent new sub-national arenas within which state power is being fundamentally rescaled, and as such is predominantly urban focussed. His work is, however, situated in a very rich conceptual literature, which we feel can be drawn on to analyse state restructuring in rural areas as well. Brenner builds his analysis of changing state forms around Jessop's strategic-relational approach (SRA) to state theory. The SRA has been identified as "perhaps the most theoretically sophisticated discussion of the state currently available" (Kelly, 1999: 109), and for Brenner its "theoretical linchpin" is centred on the notion that the state's spatial form represents the "arena and outcome of spatially selective political strategies" (2004: 84, original emphasis). This insight, with its stress on the spatially mediated construction of political strategy, is a crucial one which can be used as a framework for analysing the changing contexts and consequences of state power in rural areas. As we shall see in the next section, such analysis involves examining how political strategies influence state form and structure and how changes in state structures help to produce changes in political strategies. A focus on this dialectical relation between political strategy and the state's territorial and scalar form does not mean merely addressing the "trite claim that institutions exist in time and space" or analysing the way in which "attempts to transform [state institutions] must be coordinated over time and space" (Jessop, 2001: 1227). Rather the SRA can help us reveal how the twin notions of territoriality and scale are built into the very fabric of the state and how changes in these - through local government restructuring, for instance - will impact on the material and ideological practices of the state. Although we use examples drawn from the UK to illustrate this, the conceptual and theoretical insights of the SRA can be used to analyse state restructuring more widely (see Gualini, 2004, on Italy and Lagendijk, 2007, on the EU for instance), and we would stress its applicability in helping to understand the recent restructuring of rural local government in countries such as Australia, Canada, USA and New Zealand (see respectively Cheshire 2006; Douglas, 2005; Radin et al, 1996; Welch, 2002).

Jessop's development of the strategic-relational approach emphasizes three interrelated points $(1990,2008)$, and we will deal with each in turn. Firstly, the state should be viewed in relational terms and hence "state power reflects the prevailing balance of forces 
as this is institutionally mediated through the state apparatus" (Jessop, 2002: 40). The state, therefore

has no power - it is merely an institutional ensemble; it has only a set of institutional capacities and liabilities which mediate that power; the power of the state is the power of the forces acting in and through the state. These forces include state managers as well as class forces, gender groups as well as regional interests, and so forth (Jessop, 1990: 269-70).

Of course, the state is more permeable to certain social forces than others. We will explore the notion of strategic selectivity below, but for now will just note that like all structures, and indeed all institutions, states have historically specific 'spatio-temporal extensions'. That is, they emerge in specific places at specific times, they operate over particular scales and territories and they have certain temporal horizons of action (see Jessop, 2008: 45-6). And crucially for us here, because of its particular territorial nature, the social and political forces that can legitimately gain access to particular parts and branches of the state are spatially bounded - and to a certain extent - scale dependent. In other words, the dominant social forces operating in and through the state will be potentially altered by changes in the form and structure of the state, and any territorial restructuring, such as local government restructuring, is likely to impact on the shape and power of these forces. In other words, those social forces which can gain access to rural local government at a particular scale (say a County), will be different from those which can gain access at other scales (say a Region or a District), and they will pursue different strategies and implement different policies as a result.

This brings us on to the second key component of the SRA. For Jessop, the existence of the state as a distinctive form of social relation does not in itself guarantee the delivery of a coherent or coordinated set of state activities. Instead, the (relative) unity and organizational coherence of the state must be created through the mobilisation and pursuit of particular state practices and projects, "which attempt to integrate state activities around a set of common, coherently articulated agendas" (Brenner, 2004: 85). In other words, the state, and the policies and activities pursued through it "constitutes a terrain upon which different political forces attempt to impart a specific direction to the individual or collective activities of its different branches" (Jessop, 1990: 268). Thus, those social forces which are able to act 'in and through' the state will seek to develop a range of political strategies which are "intended to harness state institutions towards particular socio-economic projects" (Brenner, 2004: 87). Although we can speculate that those projects pursued in rural areas will differ from those pursued elsewhere - because of a focus around relatively distinct socio-economic practices (see Cloke and Goodwin, 1992) - their particular shape and form will have to be uncovered through empirical work on the changing nature of state structures in the countryside. And as we shall see in the next section, as the territorial structure of local government changes, so too will the projects being pursued by dominant social and political interests.

The third key element of the SRA stresses the strategic character of the state. Here Jessop uses the twin concepts of political strategy and strategic selectivity to explore why the state tends to serve as a "specific political form which offers structural privileges to some but not all kinds of political strategy" (Jessop, 1990: 270). Again this is a critical question for those concerned with rural politics, where particular hegemonic groups (usually 
derived from landed, property and commercial interests) have tended to exert a longstanding control over local government and other local political institutions (see Woods, 1997 for an empirical example). For Jessop, the tendency of the state to privilege certain interests over others (usually those of dominant groups) is not structurally pre-given, but "results from the evolving relationship between inherited state structures and emergent political strategies intended to harness state institutions towards particular socioeconomic projects" (Brenner, 2004: 87). To explore this further Jessop develops the argument that the state can be analysed as "the site, the generator and the product" of particular strategies (Jessop, 1990: 260). Each element in this threefold analysis can be used to interrogate the changing nature of rural local government following reorganisation.

The notion of the state as the site of political strategies draws our attention to the ways in which it can be analysed as a territorially and functionally dispersed system, whose internal structure and mode of operation are more permeable and suitable to some types of political agents than to others. This 'differential access' means that

particular forms of economic and social systems privilege some strategies over others, access by some forces over others, some interests over others, some spatial scales of action over others, some time horizons over others, some coalition possibilities over others. Structural constraints always operate selectively: they are not absolute and unconditional but always temporally, spatially, agency and strategy specific (Jessop, 1997c: 63).

Through the notion of 'strategic selectivity' the SRA emphasises the contingent rather than structural character of state strategies - a contingency partly dependent on the state's spatial and territorial structure, and one that will be altered through processes such as local government reorganisation. Again, just how it is altered will be an empirical research question for those interested in the changing nature of rural politics and rural political power.

The state is the generator of strategies because it "serves as an institutional base through which diverse societal forces mobilise...strategies and...projects" (Brenner 2004: 87). Moreover, in the case of local government, this institutional base can be strengthened and draw legitimacy from the electoral process. In rural areas, it can also be reinforced by the long-standing nature of political dominance by the 'property, paternalism and power' (Newby et al, 1978) of landed agrarian interests or other dominant fractions of capital - the potential of the state to generate particular strategies will thus be heightened if the same socials forces can secure control over an extended period. But it can also be reduced, as we shall see in the next section, if reorganisation results in new patterns of political control and the introduction of new political strategies.

The state is also the product of strategies in that its "structure and modus operandi...can be understood in terms of their production in and through past political strategies and struggles" (Jessop, 1990: 261). Thus, the present state form is partly the product of past strategies or, more accurately, the product of the interaction between past patterns of strategic selectivity and the strategies adopted for their transformation. In this sense, the structures of rural local government are constituted through past political activity, but at the same time provide an already partitioned geography within which current activity takes place. The question raised once more is how this activity might change as the geography of the state changes via local government reorganisation. 
Overall, if developed substantively, the strategic-relational approach provides some key implications and insights for the ways in which we might analyse and understand the restructuring of rural local government. It emphasizes that any substantive unity which different branches of the state possess only derives from (but can never be guaranteed through) specific political projects. This in turn means that "state-building is not a once-andfor-all process but is constantly reiterated within specific but variable institutional limits" (Jessop, 1990, 268). Brenner warns us however, that in such 'state-building' the "spaces of state power are not simply 'filled', as if they were pre-given territorial containers" (Brenner, 2004: 76). Instead new state spaces are "actively produced" through "socio-political struggles articulated in diverse institutional sites and at a range of geographical scales" (ibid: 76). This means that following any restructuring, the state spaces inscribed by local government will always have to be 'actively produced', and that the 'socio-political struggles' which produce them will involve different social and political forces operating over different territories and at different scales. We have noted earlier how local government reorganisation in Shropshire and Cornwall has already set in train new governance structures, institutions, networks and actors, all operating over new territories and at new scales. The SRA then draws our attention to the ways in which new state spaces are 'actively produced' following reorganisation, and to the ways that this production is dependent on a set of strategically and spatially selective strategies.

It will also be dependent on a set of discursive constructions and interventions. Jessop reminds us in his more recent work that "strategies are always elaborated in and through discourses" (Jessop, 2002: 36), and this reinforces some earlier suggestions about the importance of what he terms 'spatial imaginaries'. This term refers to the "demarcation of a local economic space with an imagined community of economic interests" (Jessop 1997c: 61). The inscription of such an imaginary is twofold, relating not just to the discursive demarcation of a manageable economic space, but also to the creation of an "illusory community whose interests and social cohesion are to be managed by the state" (Jessop, 1990: 346). We can extend the concept beyond the economic by suggesting that state projects and strategies will use a 'spatial imaginary' as a means of not just describing the economic space over which they claim competence, but also of describing the social, political and cultural nature of that space. This draws on Hay's ideas that "actors are reflexive and strategic and they orientate themselves and their strategies towards the environment within which their strategic intentions must be realised" (Hay, 2002: 9). An important factor in such orientation is "how the wider context and the consequences of past and possible future actions are discursively mediated and understood. In each case, only certain ideas and narratives shedding light on the situation will prevail (Lagendijk, 2007: 1196). In this sense state projects and strategies will rest on a prior, and ideally stable, identification of suitable objects of intervention and activity. Thus within any given local government territory the notion of what constitutes the 'rural' will be constructed in a particular form, as more (or less) amenable to certain types of state strategies, and orientated towards certain policy combinations. In some cases this might involve the commodification of the countryside for tourism and leisure industries, in others it might involve extensions of the digital highway to promote science parks and growth poles. In some it might include the building of housing for commuters, while in others it might centre around an exclusionary politics of 'conservation' and planning restrictions (see Murdoch et al, 2003 on the variegated or 'differentiated countryside'). Whatever the activity, "imaginaries serve to define subjects and objects of regulation and to articulate visions 
underpinning particular strategies and projects" (Lagendijk, 2007: 1199). Once again, as the nature and territory of particular rural local governments are altered through reorganisation, then the imaginaries which are used to construct different types of state projects, and different objects of governance, will change. We will again trace this process in the next section.

Given that the new local authorities in England are only becoming operational as we write, it is too early to analyse the new state spaces and new state strategies forged by contemporary local government reorganisation. We can, however, look at the previous 'set piece' reorganisation of local government in Wales over a decade ago to pull out the ways in which a strategic-relational approach can help us understand the shifting sites and scales of state activity. We will then be better placed to apply that conceptual framework, not just to contemporary reorganisation in the UK, but also to rural state restructuring elsewhere.

\section{Understanding local government reform - the example of Wales}

The strategic-relational approach then, offers a way of examining the state as an ensemble of socially embedded and socially regularised institutions, social forces and political practices (see Jessop, 2008; 1997c; Collinge, 1996; Jones, 1997; MacLeod, 1999; MacLeod and Goodwin, 1999a,b). It is a perspective which has developed "a view of state power as a social relation which is reproduced in and through the interplay between the state's institutional form and the changing nature of political forces" (Jessop, 1997b: 23-24). Such an analysis draws our attention to the politically constructed strategies - situated at various spatial scales - which help to mould the contemporary state: to how these might take a particular form in rural areas; and to how they might be changing in the face of local government reorganisation. In addition, it draws attention to the development and deployment of these particular projects and paradigms through an analysis of what Jessop calls the 'micro-physics' of power - the channels through which state projects are pursued and the connections into wider society through which state power is actually realised and implemented (Jessop, 2008; 1997c: 59). This approach opens up new objects and avenues of research and introduces new themes for those interested in the changing nature of state power in the contemporary countryside.

This section uses the case study of Ceredigion County Council in rural West Wales to examine the effect of local government reorganisation in 1996 on the relations between the changing structures and institutions of local government and the changing state strategies of those social groups and political forces which were dominant in this particular peripheral rural society. We use this example from a previous round of local government reorganisation to show how the SRA can help to explore the formation of new objects of governance, new state strategies and new political projects. Although we can begin to discern changes in each of these as a result of the current reorganisation in England, it is too soon to analyse their full extent.

In 1996 Ceredigion changed from a District to a County council, and assumed responsibility for delivering the complete range of local authority services that were previously distributed between the County (Dyfed County Council) and District (Ceredigion District Council) levels (see Figures 2 and 3). Politically, it was unique in Wales in being the only Unitary County run by a formal Independent political grouping, with council leaders stressing that Council policies were constructed to serve the 'whole community' rather than 
being the result of Party Manifestos and policies determined elsewhere (an immediate 'strategic selectivity' used to construct a set of 'local' policies in opposition to an imagined urban bias in the formal political parties). 31 of the 44 councillors who sat on the previous District Council were initially elected to the new County Council on 1 April 1996 (Balsam, 1999). In essence, those who ran the previous District Council, with its far fewer powers, took over the running of the new County Council. Around a third of councillors were returned unopposed without an election in both 1995 and 1999, and less than one in ten of the councillors were female. In these senses, and despite its new powers, Ceredigion fits our ideal(ised) notion of a traditional rural local authority - controlled by a long-standing and secure political elite strongly associated with agriculture, non party-political, patriarchal if not paternal, and closely connected to 'the community'.

\section{INSERT FIGURE 2 HERE}

\section{INSERT FIGURE 3 HERE}

\subsection{Objects of governance}

The SRAs stress on political strategies and political projects draws our attention to the way in which suitable objects of governance are constructed. Rather than taking these as given, we need to examine how different elements of economic and social life are actively constituted as suitable objects of governance. This will of course vary from place to place, and rural society has the potential to exhibit quite different objects of governance to those found operating in more metropolitan areas. There are several aspects to such constitution. First, the material and discursive construction of the object itself has to be considered, and then attention has to turn to the appropriate scales and strategies of intervention. In any given area of policy there will always be two interlinked aspects to this construction: the local aspect of policy has to be defined in relation to any supra-local considerations, and the boundaries of the policy area itself have to be drawn in relation to other local considerations.

Hence if we use economic policy as an example, we can ask how local government defines and constructs a particular type of economic space as suitable for specific kinds of development strategy. State institutions play a critical role here, not just in constructing a certain picture of their local economy, but in delineating the 'problems' which that economy faces and in defining attendant policy solutions These questions are particularly pertinent in rural areas, where the traditional basis of a land-based economy has eroded and new attempts at generating a diversified and 'value added' economy are being promoted.

Turning to Ceredigion, the reorganisation of local government meant that decisions over which areas of economic and social activity were deemed to be suitable objects of governance took on a particular urgency (Ceredigion Independent Grouping, 1995; Ceredigion County Council, 1996, 1998, 1999). Importantly - and in the context of the contemporary reforms in parts of rural England - those strategies and policies which were initiated and developed over the larger institutional territory of Dyfed were abandoned in many instances, and Ceredigion County Council had to consciously construct new objects of 
governance suited to its new territorial functions ${ }^{1}$. Such changes can be exemplified through examining how economic and social policy was re-defined following reorganisation.

In terms of economic policy, the new council placed significantly more emphasis on indigenous enterprise and business development (Ceredigion Independent Grouping, 1995) in stark contrast to Dyfed's previous policy of attempting to secure inward investment by developing factory estates (Dyfed County Council, 1994). In the words of the Leader of the Council at the time:

I don't think that this area is suited to large-scale industrial development. I think that we need to make better use of the raw materials that we have here. You look at what has happened in Felinfach for instance, where they are using local raw materials (milk) and they manufacture cheese, butter etc., and the by-products are then used to produce cattle food. That is the sort of thing that I feel would be successful in an area like Ceredigion.

Indeed, there was a general perspective framed through subsequent economic development strategies that the economic future of Ceredigion depended on developing technology-intensive indigenous industry. Efforts were made by the new local authority to work with the former Rural Division of the Welsh Development Agency (WDA) to develop the use of technology in the county, and proposals for a Welsh-orientated telebanking service were taken forward, as well as developing electronic commerce facilities for smallmedium sized companies (SME's) (ibid.).

The peripherality of the new County was felt to be especially problematic. As a larger territory, the economic space of Dyfed reached down to the end of the accessible M4 corridor (in South West Wales), which made inward investment a feasible strategy. It was a strategy however, that was not felt to be suitable for the new County:

The county's peripheral location and its poor transport links with national and regional strategic routes makes it difficult to attract inward investment and development, particularly in the manufacturing sector......the economy during the Local Plan period will depend heavily upon agriculture and service industries (Ceredigion Local Plan, 1998, Section 8.10: 50).

So the new council following local government reorganisation constructed an object of governance that was much more centred on electronic commerce, education and tourism, a fact which was outlined in the Local Plan (Ceredigion County Council, 1998) which stated that "the county council is keen to facilitate the further development and expansion of the county's higher and further education establishments" (Ceredigion Local Plan (1998), Policy EO6: 53), and by the (then) Chair of Economic Development and Tourism:

..the only economic development in Ceredigion since the end of the War has been in education, and really we should concentrate on that.......our only hope and

\footnotetext{
${ }^{1}$ Dyfed was the former higher-tier authority responsible prior to the 1996 reforms for the 'strategic' delivery of services such as education, transport, social services, structural planning and economic development. It covered the District Authorities of Ceredigion, Carmarthen, Dinefwr, Llanelli, Preseli and South Pembroke. When Dyfed was abolished in 1996 only Ceredigion gained unitary status - the latter two districts were combined in the new County of Pembrokeshire, and the other three now form Carmarthenshire.
} 
salvation is to see a definite expansion in the area of University education. It is very, very successful. It employs a great deal of people. Pembrokeshire has got the oil industry, Ceredigion has got education. That is what we have got, whether you like it or not. Powys has got bugger-all.

In addition, the new council commissioned work on the development of tourist projects in the area which subsequently resulted in the Wales Tourist Board (WTB) releasing $£ 1,000,000$ for the development of seventeen projects and the creation of 53 full-time jobs (Middlehurst, 1996). Subsequent bids to the EU Objective 1 Programme between 2001 and 2008 confirmed a continuation of this approach.

Despite this reshaped economic agenda, the overall construction of suitable objects of governance in Ceredigion tended to result in the Council highlighting a more social and cultural agenda, and this was reflected in the subsequent bids made for EU Objective 1 funding between 2001 and 2008, many of which were focused around support for local indigenous business development, local heritage and culture (for example, the 'Ystwyth Trail' - $£ 625,000$ grant; and the 'Spirit of the Miners' project - $£ 149,000$ grant (http://www.euceredigion.co.uk/approved eng.html). Put simply, the Council felt that it was not sufficient to import policy solutions from elsewhere, as these were thought to be inappropriate due to Ceredigion's social and cultural 'distinctiveness'. As a result this meant the subsequent construction of distinctive objects of governance incorporating social and cultural issues were elevated to a higher degree than might be expected - a fact initially highlighted in the reorganisation period when it became apparent that cultural services would survive in the face of limited finances which threatened to result in cuts in a number of different service areas. As the (then) Council Leader noted:

I think that there is awareness in this county of the need to develop cultural services: it is very, very unlikely that we will be starving that particular service of monies.

The greater emphasis placed on social and cultural issues were also reflected in the nature of the new authority's two bids (amounting to $f 4$ million in total) to the former Welsh Office Capital Challenge scheme. These bids were for new local authority office accommodation and for a Welsh-medium secondary school to move to a new site ${ }^{2}$ (Rotheroe, 1996). Major economic development projects were not submitted, in contrast to the bids from other unitary authorities in Wales. Such strategies confirmed the perspective held by the (then) Council Leader who stated that:

\section{Education....and Social Services must have priority over Economic Development initiatives.}

The use of the word 'must' is interesting - there is of course no necessary reason why any set of policies should have priority over any other, as long as statutory obligations are met. The formulation of specific policies is a political decision which is linked to the particular strategies and projects of dominant political groupings. This was clearly evident in Ceredigion with regard to the formulation of housing policy. The provision of social housing in rural areas has never been seen as such a priority service as it in cities, although this is

\footnotetext{
${ }^{2}$ This latter bid was successful in achieving funding, albeit in 1998/99.
} 
itself linked to the dominant construction of the rural as a sanitised and problem-free space, in which the homeless are either hidden or displaced to the nearest urban area (Milbourne, 2006; Cloke, Milbourne and Widdowfield, 2002). In Ceredigion however, the issue of housing policy assumed a heightened significance. This was because housing was constructed as an object of governance not just in terms of meeting statutory housing obligations, but also as a critical component of cultural and linguistic policies.

Providing low-cost homes for 'local' people was seen as one way of stemming a decline in the Welsh language, and the Council proposed that residency restrictions should be used to limit the availability of social housing for 'outsiders' (The Cambrian News, 3 November 1995). The favouring of local people for social housing, in contrast to the statutory demands of the homelessness legislation, was felt to add stability to local communities in rural Ceredigion, as well as providing a means of retaining Welsh speakers in the area. In the words of the Liberal Democrat Leader during the reorganisation period:

We believe that there should be more social housing made available for locals - full stop. At present the housing associations are not providing enough accommodation for young Welsh people who have lived in the area all of their life.

Indeed, the Council did not favour other housing policies available to it, such as those focussed towards the provision of a different 'type' of social housing (for example, sheltered accommodation for the homeless or the provision of drug rehabilitation centres), as such issues were felt to stem from problems associated with individuals and areas outside Ceredigion. So what subsequently emerged was housing policy being constructed in a very specific relation both to extra-local factors (incoming migrants), other local issues (language, culture and communities) and also historical factors (a perception of a return to the pre-1974 days of the old Cardiganshire local authority, which covered the same territory as the new Ceredigion authority and had specifically-tailored policies for this particular rural space). As with other service areas, housing policies were actively shaped and constructed by political considerations at the local level, linked intimately to hegemonic projections of community stability and cultural identity (Rotheroe, 1997).

To conclude this section, the SRA highlights how different elements of economic and social life may be constructed as 'suitable' objects of governance by social and political forces operating at specific scales and through specific strategies. If we take the Ceredigion example, we can expect the objects of governance being promoted in many rural areas of England (and in broader contexts) to change considerably following local government reorganisation. In particular, it will be interesting to explore the extent to which cultural concerns increasingly influence the nature of both social and economic policies. Furthermore, the peripherality of rural areas such as Northumberland and Cornwall in England- relative to areas such as Wiltshire and (significant parts of) Shropshire - may also impact on the extent to which 'externally' or 'internally' focused development strategies are prioritized. Interestingly, variation may become apparent in England between those new unitary authorities based upon former county arrangements (5 instances) and those based predominantly on former districts (4 instances). In this respect, Ceredigion shows how the move to a smaller unitary authority resulted in more endogenous economic development strategies. However the opposite may be true for some of the new larger unitary authorities in England, pointing to the need for further research to uncover the 'active production' of these new rural state spaces. 


\subsection{Political strategies and hegemonic projects}

One of the defining features of the SRA is its stress on the construction of political strategies and projects, and its constant examination of the interplay between these and particular sets of institutions and agencies. It is this interplay which helps define the limits and boundaries of political power. Neither any given project, nor any set of institutions, will be effective on their own, and the most powerful political strategies are delivered through a strong combination of the two. However, the same institutions will not necessarily be suitable for delivering different projects - hence the constant flux in state structures as dominant groups seek a state form which can best deliver their preferred projects.

It is here that the effort to construct a particular 'hegemonic project' (in part through the mobilization of a social base of support) can prove decisive in resolving (albeit temporally and unevenly) the conflicts between particular interests (Jessop, 1997c: 62). A hegemonic project

...mobilizes support behind a concrete program of action that asserts a contingent general interest in the pursuit of objectives that explicitly or implicitly advance the long-term interests of the hegemonic class (fraction) and thereby privileges particular economic-corporate interests compatible with this program while derogating the pursuit of other interests that are inconsistent with the project (ibid: 62).

At the time of local government reorganisation in Ceredigion, there were longstanding hegemonic projects revolving around the political power of landed and agricultural interests to serve the 'general interests' of a self-defined local community. One local councillor at the time summed this up succinctly:

Most of the Independents tend to be rural farming-types so I suppose that they don't want to see their small schools shut, and they want more support for agriculture and local businesses. They also want to see their old mates getting planning permission wherever they want.

In the period following reorganisation in Wales, leading local politicians in Ceredigion thus refused to respond to central government initiatives designed to promote closer ties between local governments and their communities, claiming that the presence of the ruling Independent group ensured that they were already working in the best interests of the whole community rather than any fraction of it. The promotion of this illusionary general interest was extremely successful politically - so much so that when the (then) Council leader stood as an Independent in the Welsh Assembly elections of May 1999, he was able to beat the Liberal Democrat and Conservative candidates into third place and only lost second place to the Labour candidate by less than a thousand votes.

An idea of how this appeal to the general interest was constructed may also be gained from an examination of planning policy in the area since the early 1990s. Research by Cloke (1996) found that the pre-1996 Ceredigion District Council had the second highest level in Wales of planning decisions taken contrary to the advice of Council officers about complying with local or structure plans. The rationale given by the Leader of the previous District Council for this discrepancy between advice and action was as follows: 
As far as the elected people of Ceredigion are concerned, the structure plan document was a badly compiled one...If we strictly follow the structure plan policies it means that we will be driving people out of the rural areas...That is not the sort of community that we are trying to form and preserve in Ceredigion. We have the culture, language and economic future of Ceredigion at heart. They are the reasons why we are acting, as you say, outside the policies contained in the structure plan (quoted in Cloke, 1996: 298).

Cloke concluded that rural planning in Ceredigion "remains targeted towards some social groups and not others by a culture of decision making which too often equates local needs with landowning agricultural interests" (Cloke, 1996: 307). Analysis of the Local Plan for Ceredigion which was produced in the period following reorganisation revealed that this approach had - to a significant extent - continued with the creation of the new authority (Ceredigion County Council, 1998), leading to tensions with the former Welsh Office. This was widely acknowledged as being a key issue at the time, as indicated by another local councillor:

The (former) Welsh Office are persistently getting involved in our planning because Ceredigion appears to be incapable of keeping out of trouble in terms of following sensible guidelines. There are certain things in the Draft Ceredigion Local Plan which relate to the Welsh language and house building for local Welsh people which the (former) Welsh Office will never accept.

The majority of Ceredigion councillors nevertheless supported farming families who wanted planning restrictions lifted on bungalows which had been built in the open countryside (and which had been constructed on the original understanding that they would be used only by agricultural workers). In this respect, the Council at the time agreed that they only had to put the properties with Estate Agents for one month in order to identify whether there was still a demand for farm workers' homes when they were offered for sale (The Cambrian News, 15 May 1997). The former Welsh Office, on the other hand, stated in planning guidance that a period of around nine months was required (under Planning Policy Guidance (PPG) Note 3).

So the community which the new Council was consciously trying to "form and preserve" in the period following local government reform was a very selective rather than a general one. The interests of the indigenous rural community, based around agriculture and self-defined notions of Welsh culture was privileged by the hegemonic project that emerged post-reorganisation in Ceredigion. The SRA allows us to focus on and uncover such strategic selectivity. This was also the requisite social base that ensured the continued political power of the dominant political group, and despite the council moving from District to County status in 1996, political control remained in virtually the same hands. Perhaps this is not wholly surprising given that such a distinctive political culture in the area appears to be longstanding. Madgwick's research on the 'politics' of local government in West Wales noted in the period prior to the 1974 reorganisation that "Cardiganshire County Council reflected old Welsh rural Cardiganshire, rather than the more diverse, mobile and anglicised areas" (Madgwick, 1973: 182). 
A focus on the strategic selectivity of particular hegemonic projects draws our attention quite specifically to the ways in which political and moral leadership can be mediated through the introduction of new structures of rural local government. Over time however, this political leadership has changed - and perhaps in similarity to what we saw in the post-1974 phase - there has been a gradual decline in the power of the Independent grouping, which lost overall power of Ceredigion County Council in 2004. Interestingly, however, the social base of support for a hegemonic project based around self-defined notions of Welsh culture, agriculture and farming interests has been retained to a significant degree, prompting further recent conflict with the Welsh Assembly Government over planning policy (Ceredigion County Council, 2006). The lessons then, for England are to examine how the structural and strategic changes ushered in through local government reorganisation impact on one another. As Jessop puts it, the ability of different social forces to pursue their interests through the state "is not inscribed in the state system as such, but in the relation between state structures and the strategies which different forces adopt" (Jessop, 1990: 260). Following any local government reorganisation, unpacking this relationship between structures and strategies will be central for those seeking to understand changes in rural policy and politics.

\subsection{Constructing new spatial imaginaries}

As we saw in Section 3, the SRA also draws our attention to the ways in which institutions seek to demarcate a manageable space of action which is amenable to effective governance practices through "the role of the spatial imaginary" (Jessop 1997c: 61). The key is to investigate how political actors attempt to specify an economic and social space amenable to their preferred governance practices, given changes to the institutional spaces that they have control over and responsibility for. With local government reorganisation, the new councils that were created in Wales - and more recently within England - have had to re-define and re-negotiate the 'spatial imaginaries' over which they are governing. This is far more complex than simply fitting an economic and social strategy into a given territorial container, and the task has been made more difficult within an increasingly 'congested state' (see Sullivan and Skelcher, 2002). Indeed, with the election of the New Labour Government in 1997 and the process of devolution, a whole new range of mechanisms of governance have been introduced. In Wales these included an elected Welsh Assembly and associated regional economic partnerships, the initial reformulation and subsequent abolition of the Welsh Development Agency (WDA), which itself replaced the Development Board for Rural Wales (DBRW), the reformulation of the European Structural Funds to include West Wales and the Valleys as areas eligible to receive Objective 1 funding and the more recent creation of Local Health Boards, Community Strategy Partnerships (CSPs) and Local Service Boards (LSBs) (Pemberton and Lloyd, 2008).

In an English context, a similar proliferation of agencies of regional and local governance has emerged including Government Offices (GOs) for the regions (which predate New Labour), Regional Development Agencies (RDAs) and Regional Assemblies, Interregional growth strategies, local strategic partnerships (LSPs) and more recently the development of Sustainable Community Strategies (SCSs) and Local Area Agreements (LAAs), as well as new Economic Prosperity Boards (EPBs) which will be responsible for formalising sub-regional Multi Area Agreements (MAAs) (ibid.). Indeed it could be argued 
that the complexities of both English and Welsh governance present considerable difficulties in dealing with the governance of complexity.

With regards to the case study of Ceredigion, it recognised at a relatively early stage during the reorganisation process in Wales that it would have to work in partnership with others, especially to promote the economic development of the area. However, it experienced a number of difficulties in establishing working relationships with other agencies and organisations such as the former WDA, the regional economic partnership (the Mid Wales Partnership) and neighbouring unitary authorities, as well as local communityfocused LEADER groups. In the face of such complexity, council officials in the new authority recognised that "parochialism within the county is a problem" (Ceredigion County Council, 1999: 5).

In many instances, cultural and social considerations, rather than economic ones, determined the choice of partners, which affected the Councils' ability to specify a suitable economic space for manageable intervention. In the words of one leading Council member at the time of the reforms:

We have set up very few partnerships so far, except for those forced upon us, such as the Fire Brigade and the Police. I think that partnerships will have to be set up, especially with other authorities to provide specialist educational services, for example. We will probably work with Carmarthenshire and Powys, but probably not with Pembrokeshire as our policies over bilingual education will inevitably clash with theirs.

Extending the spatial imaginary beyond the boundaries of Ceredigion proved to be especially difficult. One senior council officer noted that:

The split (geographical) personality of the council means that it will have to work with Carmarthenshire, Pembrokeshire and Powys.

But interviews conducted with the Council's Chief Executive and other officers and members highlighted a range of other spatial imaginaries that existed. For example, the (then) Chief Executive felt that Ceredigion and Powys, because of their (perceived) shared rurality, had far more in common with each other than Ceredigion had with Carmarthenshire and therefore wished for links with Powys County Council to be enhanced. Other officers and members of the new authority disagreed and argued that the new Council should concentrate on linking with Carmarthenshire and other institutions to the south because of accessibility problems in having to cross the Cambrian Mountain range to link with Powys, and also because economic development in the south of Ceredigion was dependent to an extent on the fortunes of northern Carmarthenshire and Pembrokeshire which lay at the western end of the M4. Hence the Council was unable to easily discern any identifiable spatial imaginary beyond its own boundaries - a point which was made very clearly by a leading councillor at the time who commented that:

Ceredigion will work very little with Carmarthenshire as there is a different type of Welsh person in the area, whilst Pembrokeshire can be ruled out as it is 'little England beyond Wales'. 
We were also told by a Senior Director on the new authority that Ceredigion would not work with any of the North Wales authorities as "it had little in common with them". Thus although partnership working has become increasingly the norm in rural areas (see Osborne et al, 2004; Edwards et al, 2001), the particular state strategies and hegemonic projects being promoted in some rural areas make these difficult to put into practice. Consequently, Ceredigion County Council initially retreated into a rather narrow political space that it felt it could control, rather than becoming engaged in partnerships that potentially would deliver different sets of policies. Having said this, the publication of the Wales Spatial Plan in 2004 (Welsh Assembly Government, 2004; updated 2008) which was created in an attempt to join up activities nationally, regionally and locally, has subsequently formalised Ceredigion's position within a broader 'central Wales' region (one of six Spatial Plan areas). Furthermore, such an area has purposively not been defined by administrative boundaries, in order to promote local authority involvement in more than one Spatial Plan Area Group, and to facilitate inter-council co-operation and partnership working.

Hence the lesson for analysing contemporary local government restructuring in England and elsewhere is recognising the extent to which the new authorities are able to effectively re-define their spatial imaginaries, as well as appreciating the complex processes involved, including the interaction with regional and/or national-level institutions. This, again, may well vary depending on the extent to which the new unitary authorities are based on former Counties or Districts and hence whether processes of either 'decentralisation' or 'centralisation' are most evident. For example, in Cornwall, Durham, Northumberland, Shropshire and Wiltshire, reorganisation into unitary authorities has been more a process of centralisation with the abolition of district councils, whereas in Bedfordshire and Cheshire, four smaller unitary authorities have emerged as part of a decentralisation process from two larger county councils. In turn, this may impinge on the relative capacity and effectiveness of the new institutions at creating partnerships beyond their own boundaries.

In many ways reorganisation in Ceredigion facilitated a more inward looking polity at the time as the dominant interests not only survived local government reorganisation but if anything became more entrenched:

Basically, a lot of people on this (new) council think that we are going back to Cardiganshire as it was pre-1974. They believe that they were $f^{* * * * d}$ around by Dyfed and now everything will be great because we are going back to how we used to be. It is a very independent county. People want to stand up on their own two feet, and they want to do things themselves. They really don't want people meddling in their affairs, probably as a result of the geography of the county. If you think about it, to come into Ceredigion you either have to come over the mountains or come in via the sea.

This statement from a leading councillor at the time clearly highlights how those with dominant interests constructed the area as distinct and different from other places - a construction which was given more force by the shift of the County to unitary status. The geography of the county has of course little to do with the social, cultural and political forces which promoted such a construction. The area is less than two hours from Cardiff, Manchester or Birmingham and hardly isolated in the sense conveyed above, but the distrust of others has arguably hampered the Council's ability to manage the governance of 
complexity. It will therefore be interesting to see how old and new political cultures mesh together in England. As we have seen, both Shropshire and Cornwall are using reorganisation to promote and give increasing prominence to the local delivery of services given the centralisation process that has taken place into a single unitary authority, but how effective this proves will to some extent depend on the capacity of these new service areas to fit within a broader county-wide institutional structure. This is also a key issue in other parts of the world (such as Australia, Canada and New Zealand), which have seen the removal of services from rural communities and small towns through similar processes of centralisation.

\section{Conclusion}

Through drawing upon Jessop's SRA framework, this paper has sought to provide new theoretical and empirical insights into the changing nature and shape of rural local government and the local state both in the UK and beyond. Echoing Brenner's (2004) idea of 'new state spaces' the evidence from the reorganisation of local government in Wales - as well as emerging evidence from the impact of contemporary processes of reform in England (and indeed elsewhere) - confirms that state power in rural areas is being significantly rescaled, with some important consequences.

Following such rescaling, the changing institutions of the state have both informed, and been informed by, the emergence of new political forces and strategies. Indeed, we saw how in Ceredigion the objects of governance that were promoted following local government reorganisation differed markedly from those pursued before, as the new ruling political group sought to mobilise a particular social base within a new territorial structure. In this case the objects of governance which were developed within a much smaller institutional and political space prioritised social and cultural issues rather than economic ones.

Consequently, the implication that arises for analysing the impact of the restructuring of rural local government is the extent to which structural changes may provide opportunities for certain political interests in rural areas to pursue and implement new sets of policies that would not have been possible previously. But it must be recognised that structural changes alone are not enough to promote particular policy trajectories these will always be developed through specific political strategies, and it is the relationship between structure and strategy that is crucial to investigate. Critical amongst these strategies is the initial framing of distinct objects of governance and the paper highlighted how these can change following the territorial restructuring of rural local government. Whilst further research is required on the impact of such changes, this also needs to be considered within the context of the increasing complexity of (economic) governance both in the UK and beyond (Jessop, 2002). Attention is drawn to how political actors within a restructured rural local government are attempting to re-define their 'spatial imaginaries'; to the extent to which these are inward or outward looking; and to the subsequent impact this has on their ability to demarcate suitable economic spaces for intervention both within and beyond their own boundaries. Their success at such redefinition will be crucial in securing support and resources for their emergent political strategies.

Indeed, in the context of the UK, the recent sub-national review of Economic Development and Regeneration (HM Treasury, 2007), as well as the work of policy think 
tanks on the impact of a future change of national government (New Local Government Network, 2009) has highlighted how rural local government will arguably play an increasingly important role in delivering economic regeneration, in conjunction with a range of regional and sub-regional partnerships. Critical to the success of areas such as Shropshire and Cornwall in this process will thus be their ability to work smoothly and effectively within these new structures. Nevertheless, changes to both the institutions and the strategies of the rural state will ensure the continued contestation of political and accumulation projects in various parts of rural Britain. As outlined above, we feel that the SRA approach provides a useful framework within which to analyse and ultimately interpret the changing shape of such projects. Far from being enduring, stable and traditional, the politics of rural local government are now in a phase of upheaval and uncertainty as different political groups in the UK and beyond struggle to implement their preferred strategies across new territories and through new institutional structures. Brenner has recently pointed out that it "seems likely that research on processes of state rescaling...will continue to gain intellectual momentum" (2009: 132). It would be a welcome, and very positive, development if studies of state rescaling in rural areas were able to contribute to such momentum - both for rural studies and for those interested in the state.

\section{References}

Amin, A., 1999. An institutionalist perspective on regional economic development. International Journal of Urban and Regional Research 23 (2), pp. 356-378.

Balsam, D. (Ed.), 1999. Wales Yearbook 1999, HTV, Cardiff.

Brenner N., Jessop, B., Jones, M., and MacLeod, G., 2003. State space in question. In: Brenner, N., Jessop, B., Jones, M. and MacLeod, G., Editors, 2003. State Space: A Reader, Blackwell, Oxford, pp. 1-26.

Brenner, N., 2004. New State Spaces: Urban Governance and the Rescaling of Statehood., Oxford University Press, Oxford.

Brenner, N., 2009. Open questions of state rescaling. Cambridge Journal of Regions, Economy and Society 2, pp. 123-139.

Byrne, T., 1994. Local Government in Britain (6 ${ }^{\text {th }}$ Edition)., Penguin, London.

Ceredigion County Council, 1996. Service Delivery Plan., Ceredigion County Council, Aberystwyth.

Ceredigion County Council, 1998. Ceredigion Local Plan., Ceredigion County Counci I, Aberystwyth.

Ceredigion County Council, 1999. Ceredigion Economic Development Strategy 1998/99., Ceredigion County Council, Aberystwyth. 
Ceredigion County Council, 2006. Further Consultation on UDP: October 2006, available at http://www.ceredigion.ugov.uk/index.cfm?articleid=3032; accessed 11 April 2009.

Ceredigion Independent Grouping, 1995. People and Common Sense Before Politics., Ceredigion Independents, Aberystwyth.

Cheshire, L., 2006. Governing Rural Development: Discourses and Practices of Self-help in Australian Rural Policy., Aldershot, Ashgate.

Cloke, P., and Goodwin, M., 1992. Conceptualizing countryside change: from post-Fordism to rural structured coherence. Transactions of the Institute of British Geographers 17 (3), pp. 321-366

Cloke, P., Milbourne, P. and Widdowfield, R., 2002. Rural Homelessness: Issues, experiences and policy responses., The Policy Press, Bristol.

Cloke, P., 1996 Housing in the open countryside: windows on 'irresponsible' planning in rural Wales. Town Planning Review 67 (3), 291-308

Cloke, P., 1997. Country Backwater to Virtual Village? Rural Studies and 'The Cultural Turn'. Journal of Rural Studies 13 (4), pp. 367-375.

Cloke, P., 2006. Rurality and otherness. In: Cloke, P., Marsden, T. and Mooney, P., Editors, 2006. Handbook of Rural Studies, Sage, London, pp. 447-456.

Collinge, C., 1996. Spatial articulation of the state: reworking social relations and social regulation theory. Paper available from author at Centre for Urban and Regional Studies, University of Birmingham.

Day G., 1998 Working with the grain? Towards sustainable rural and community development. Journal of Rural Studies 14 (1), pp. 89-106.

Department for Communities and Local Government (DCLG), 2006. Strong and Prosperous Communities: The Local Government White Paper., DCLG, London.

DCLG, 2007. Proposals for Future Unitary Structures: Stakeholder Consultation., DCLG, London.

Dearlove, J., 1979. The Reorganisation of British Local Government., Cambridge University Press, Cambridge.

Department of the Environment (DoE), 1991. The Structure of Local Government in England., London: Her Majesty's Stationery Office, London.

DoE, 1993, Press Release., 1 October 1993, p.30. 
Douglas, D., 2005. The restructuring of local government in rural regions: A rural development perspective. Journal of Rural Studies 21 (2), pp. 231-246.

Dyfed County Council, 1994. Dyfed County Structure Plan., Dyfed County Council, Carmarthen.

Edwards, B., Goodwin, M., Pemberton, S. and Woods, M., 2001. Partnership working in Rural Regeneration: Governance and Empowerment?, Joesph Rowntree Foundation, York.

Edwards, B., 1998. Charting the discourse of community action: perspectives from practice in rural Wales. Journal of Rural Studies 14 (1), pp. 63-78.

Elcock, H., 1994. Local Government (3 ${ }^{\text {rd }}$ Edition)., Routledge, Oxford.

Goodwin, M., Jones, M. and Jones, R., 2006. Devolution and Economic Governance in the UK: Rescaling Territories and Organizations. European Planning Studies 14 (7), pp. 979-995.

Goodwin, M., 1998. The Governance of Rural Areas: Some Emerging Research Issues and Agendas. Journal of Rural Studies 14 (1), pp. 5-12.

Goodwin, M., 2006. Regulating rurality? Rural studies and the regulation approach. In: Cloke, P., Marsden, T. and Mooney, P., Editors 2006. Handbook of Rural Studies, Sage, London, pp. 304-316.

Gore, T. and Fothergill, S., 2007. Cities and their hinterlands: how much do governance structures really matter? People, Place \& Policy Online 1 (2), pp. 55-68.

Gualini, E., 2004. Multi-level Governance and Institutional Change: The Europeanization of Regional Policy in Italy., Ashgate, Aldershot.

Hay, C., 2002. Political Analysis: A Critical Introduction., Palgrave, Basingstoke.

Healey, P., 2006. Transforming governance: Challenges of institutional adaptation and the new politics of space. European Planning Studies 14 (3), pp. 299-320.

Herbert-Cheshire, L., 2000. Contemporary strategies for rural community development in Australia: a governmentality perspective. Journal of Rural Studies 16 (2), pp. 203-215.

HM Treasury, 2007. Sub-national Review of Economic Development and Regeneration., HM Treasury, London.

Hoggart, K. and Paniagua, A., 2001. What rural restructuring? Journal of Rural Studies 17 (1), pp.63-80.

Holloway, L. and Kneafsey, M. (Eds.), 2004. Geographies of Rural Cultures and Societies., Ashgate, Hampshire. 
Horton, J., 2008. Producing Postman Pat: The popular cultural construction of idyllic rurality. Journal of Rural Studies 24 (4), pp. 389-398.

Hubbard, P., 2005. Inappropriate and incongruous: opposition to asylum centres in the English countryside. Journal of Rural Studies 21 (1), pp. 3-17.

Jessop, B., 1990. State Theory: Putting the Capitalist State in its Place., Polity Press, Cambridge.

Jessop, B. 1997a. Twenty years of the (Parisian) regulation approach: the paradox of success and failure at home and abroad. New Political Economy 2 (3), pp. 503-526.

Jessop, B., 1997b. Globalization and the national state: reflections on a theme of Poulantzas. Paper presented to the Colloquium 'Miliband and Poulantzas in Retrospect and Prospect', City University of New York, pp. 1-31.

Jessop, B., 1997c. A Neo-Gramscian Approach to the Regulation of Urban Regimes. In: Lauria, M. (Ed.), 1997. Reconstructing Urban Regime Theory: Regulating Urban Politics in a Global Economy, Sage, London, pp. 51-73.

Jessop, B., 2001. Institutional (re)turns and the strategic-relational approach. Environment and Planning A, 33 (7), pp. 1213-1237.

Jessop, B. 2002. The Future of the Capitalist State., Polity Press, Cambridge.

Jessop, B., 2008. State Power: A Strategic Relational Approach., Polity Press, Cambridge.

Jones, M., 1997. Spatial selectivity of the state? The regulationist enigma and local struggles over economic governance. Environment and Planning A 29 (5), pp. 831-864.

Jones, M., 1998. Restructuring the local state: economic governance or social regulation? Political Geography 17, pp. 959-988.

Jones, O., and Little, J., 2000 Rural challenge(s): partnership and new rural governance. Journal of Rural Studies 16 (2), pp. 171-183.

Jones, R., Goodwin, M., Jones, M. and Pett, K., 2005. 'Filling in' the state: economic governance and the evolution of devolution in Wales. Environment and Planning C 23 (3), pp. 337-360.

Judge, D., Stoker, G., and Wolman, H. (Eds.), 1995. Theories of Urban Politics., Sage, London.

Keith-Lucas, B. and Richards, P.G., 1978. A History of Local Government in the $20^{\text {th }}$ Century., Allen and Unwin, London.

Kelly, D., 1999. The strategic-relational view of the state. Politics 19 (2), pp. 109-115. 
Lagendijk, A., 2007. The Accident of the Region: A Strategic Relational Perspective on the Construction of the Region's Significance. Regional Studies 41 (9), pp. 1193-1208.

Leach, S., 1995. The strange case of the Local Government Review. In: Stewart, J. and Stoker, G., Editors, 1995. Local Government in the 1990s, MacMillan, Hampshire, pp. 49-68.

Little, J., 2002. Rural Geography: Rural Gender Identity and the Performance of Masculinity and Femininity in the Countryside. Progress in Human Geography 26 (5), pp. 665-670.

Mackinnon, D., 2001. Regulating regional spaces: state agencies and the production of governance in the Scottish Highlands. Environment and Planning A 33 (5), pp. 823-844.

MacLeod, G. and Goodwin, M., 1999a. Space, scale and state strategy: rethinking urban and regional governance. Progress in Human Geography 23 (4), pp. 503-527.

MacLeod, G. and Goodwin, M., 1999b. Reconstructing an urban and regional political economy: on the state, politics, scale and explanation. Political Geography 18 (6), pp. 697730.

MacLeod, G., 1999. Entrepreneurial spaces, hegemony and state strategy: the political shaping of privatism in lowland Scotland. Environment and Planning A 31 (2), pp. 345-375.

Madgwick, P.J., 1973. The Politics of Rural Wales., Hutchinson, London.

Marsden, T., and Murdoch, J., 1998 Rural Governance and Community Participation, Special issue of Journal of Rural Studies, 14 (1) pp1-117

Marsden, T., 2004. The Quest for Ecological Modernisation: Re-Spacing Rural Development and Agri-Food Studies. SociologicaRuralis 44 (2), pp. 129-146.

McHardy, A. and Simmons, M., 1995. Gummer gives unitary status to 15 towns. The Guardian, 22 March 1995, p.7.

Middlehurst, T., 1996. New monies for tourism projects. The Cambrian News, 17 May 1996, p.7.

Milbourne, P., 2006. Rural housing and homelessness. In: Cloke, P., Marsden, T. and Mooney, M., Editors, 2006. Handbook of Rural Studies, Sage, London, pp. 427-444.

Moseley, M., 2003 Rural Development, Sage, London

Mossberger, K. and Stoker, G., 2001. The evolution of urban regime theory: The challenge of conceptualization. Urban Affairs Review 36 (6), pp. 810-835.

Murdoch, J., 1998. The spaces of actor-network theory. Geoforum 29 (4), pp. 357-374. 
Murdoch, J., 2001. Ecologising sociology: Actor-network theory, co-construction and the problem of human exemptionalism. Sociology 35 (1), pp. 111-133.

Murdoch, J., Lowe, P., Ward, N. and Marsden, T., 2003. The Differentiated Countryside., Routledge, London.

New Local Government Network (NLGN), (2009). Control Shift: Alt, Insert or Delete?, London, NLGN.

Newby, H., Bell, C., Rose, D., and Saunders, P., 1978 Property, Paternalism and Power Hutchinson, London

One Cornwall, 2009. Service Delivery Areas, available at http://www.onecornwall.cornwall.gov.uk/index.aspx?articleid=42611; accessed 11 April 2009.

Osborne, S., Williamson, A., Beattie, R., 2004. Community Involvement in Rural Regeneration Partnerships: exploring the Rural Dimension. Local Government Studies 30 (2), pp. 156-181.

Pahl, R.E., 2008. The Rural-Urban Continuum. SociologiaRuralis 6 (3), pp. 299-329.

Peck, J. and Tickell, A., 1992. Local modes of social regulation? Regulation theory, thatcherism and uneven development. Geoforum 23 (3), pp. 347-363.

Peck J, and Tickell, A., 1995. Social Regulation after Fordism: regulation theory, neoliberalism and the global-local nexus. Economy and Society 24 (3), pp. 357-386.

Pemberton, S. and Lloyd, M.G., 2008. Devolution, community planning and institutional decongestion? Local Government Studies 34 (4), pp. 437-451.

Phillips, M., Fish, R. and Agg, J., 2001. Putting Together Ruralities: Towards a Symbolic Analysis of Rurality in the British Mass Media. Journal of Rural Studies, 17 (1), pp. 1-27.

Phillips, M., 1998. The Restructuring of Social Imaginations in Rural Geography. Journal of Rural Studies 18 (2), pp. 121-153.

Radin, B.A., Agranoff, R., O'Mbowan, Buntz, C.G., Ott, J.S., Romzek, B.S. and Wilson, R.H., 1996. New Governance for Rural America: Creating Intergovernmental Partnerships., University Press of Kansas, Lawrence.

Rotheroe, M., 1996. Attack on 'pitiful' education awards. The Cambrian News, 26 April 1996, p.7.

Rotheroe M., 1997. What do they know about how we live? The Cambrian News, 20 March 1997, p.14. 
Rye, J., 2006. Rural Youth's Images of the Rural. Journal of Rural Studies 22 (4), pp. 409-421.

Scottish Office, 1992. The Structure of Local Government in Scotland: Shaping the New Councils., Her Majesty's Stationery Office, Edinburgh.

Shropshire $\quad$ Council, 2009 Objectives, available at http://www.shropshire.gov.uk/shropshirecouncil.nsf/open/D983CD43EE5527B7802574A50 050EBFD; accessed 11 April 2009.

Sullivan, H. and Skelcher, C., 2002. Working across Boundaries: Collaboration in Public Services., Palgrave Macmillan, Basingstoke.

The Cambrian News, 1995. Independent leader pleads for more low cost homes. 3 November 1995, p.1.

The Cambrian News, 1997. County is ideal for telecentre. 15 May 1997, p.3.

The Electoral Commission, 2009. Unitary patterns of local government in Norfolk, Suffolk and Devon: News Release, 9 February 2009; available at: http://www.electoralcommission.org.uk/news-and-media/news-releases/boundarycommittee-news-centre/structural-reviews/statement-from-the-boundary-committee; accessed 11 April 2009.

Welch, R., 2002. Legitimacy of rural local government in the new governance environment, Journal of Rural Studies 18 (4), pp. 443-449.

Welsh Assembly Government, 2004. People, Places, Futures. The Wales Spatial Plan., Welsh Assmebly Government, Cardiff.

Welsh Assembly Government, 2008. People, Places, Futures. The Wales Spatial Plan 2008 Update., Welsh Assembly Government, Cardiff.

Welsh Office, 1991. The Structure of Local Government in Wales: A Consultation Paper., Her Majesty's Stationery Office, Cardiff.

Woods, M. and Goodwin, M., 2003. Applying the rural: governance and policy in rural areas. In: Cloke, P. (Ed.), 2003. Country Visions, Pearson Education, Essex, pp. 245-262.

Woods, M., 1997. Discourses of Power and rurality: local politics in Somerset in the $20^{\text {th }}$ century. Political Geography 16 (6), pp. 453-478.

Woods, M., 2005. Rural Geography: Processes, Responses and Experiences in Rural Restructuring., Sage, London.

Woods, M., 2008. Social movements and rural politics. Journal of Rural Studies 24 (2), pp. 129-137. 